\title{
A personalized care plan is positively associated with better clinical outcomes in the care of patients with type 2 diabetes: A cross-sectional real-life study
}

\section{Mikkola, Ilona}

2020-03

Mikkola , I, Hagnäs , M , Hartsenko , J , Kaila , M \& Winell , K 2020 , ' A personalized care plan is positively associated with better clinical outcomes in the care of patients with type 2 diabetes: A cross-sectional real-life study ' , Canadian Journal of Diabetes, vol. 44 , no. 2 , pp. 133-138 . https://doi.org/10.1016/j.jcjd.2019.05.003

http://hdl.handle.net/10138/314875

https://doi.org/10.1016/j.jcjd.2019.05.003

cc_by_nc_nd

acceptedVersion

Downloaded from Helda, University of Helsinki institutional repository.

This is an electronic reprint of the original article.

This reprint may differ from the original in pagination and typographic detail.

Please cite the original version. 


\section{Accepted Manuscript}

A personalized care plan is positively associated with better clinical outcomes in the care of patients with type 2 diabetes: A cross-sectional real-life study

Ilona Mikkola, Maria Hagnäs, Jelena Hartsenko, Minna Kaila, Klas Winell

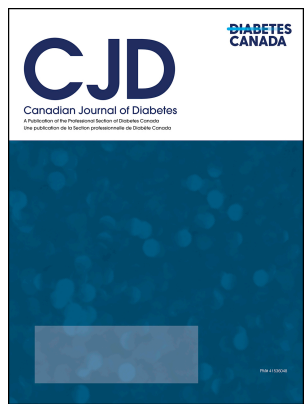

PII:

$$
\text { S1499-2671(18)30834-7 }
$$

DOI: https://doi.org/10.1016/j.jcjd.2019.05.003

Reference: JCJD 1166

To appear in: Canadian journal of Diabetics

Received Date: 21 October 2018

Accepted Date: 7 May 2019

Please cite this article as: Mikkola I, Hagnäs M, Hartsenko J, Kaila M, Winell K, A personalized care plan is positively associated with better clinical outcomes in the care of patients with type 2 diabetes: A cross-sectional real-life study, Canadian Journal of Diabetes (2019), doi: https://doi.org/10.1016/ j.jcjd.2019.05.003.

This is a PDF file of an unedited manuscript that has been accepted for publication. As a service to our customers we are providing this early version of the manuscript. The manuscript will undergo copyediting, typesetting, and review of the resulting proof before it is published in its final form. Please note that during the production process errors may be discovered which could affect the content, and all legal disclaimers that apply to the journal pertain. 


\section{A personalized care plan is positively associated with better clinical outcomes in the care of patients with type 2 diabetes: A cross- sectional real-life study}

Ilona Mikkola $^{* 1,2}$, Maria Hagnäs ${ }^{1,3}$, Jelena Hartsenko ${ }^{2}$, Minna Kaila ${ }^{4}$, Klas Winell ${ }^{2}$

${ }^{1}$ Rovaniemi Health Centre, P.O. Box 8216, FI-96101 Rovaniemi, Finland

${ }^{2}$ Conmedic, Antaksenkuja 3, FI-02330 Espoo, Finland

${ }^{3}$ Center for Life Course Health Research, Aapistie 5, P.O .Box 5000, 90014 University of Oulu, Oulu, Finland

${ }^{4}$ ORCID 0000-0002-9645-4925 Public Health Medicine, University of Helsinki and Helsinki University Hospital, P.O. Box 20, 00014 University of Helsinki, Helsinki, Finland

*Corresponding author at Rovaniemi Health Centre, P.O. Box 8216, FI-96101 Rovaniemi, Finland; tel: +358163224456; fax: +358163560041; e-mail: ilona.mikkola@ rovaniemi.fi

Running head Personalized care plan study

Key message A personalized care plan is a promising tool to improve cardiovascular risk factors and clinical outcomes of type 2 diabetes patients in the real world.

Key words cardiovascular risk, FINRISK, motivational interviewing, patient-centric care, patient record, target setting

Word count (main text) 2852

Word count (abstract) 235

Number of tables 3

Number of figures 1

Author contribution statement All following conditions are met by all authors: substantial contributions to conception and design, acquisition of data or analysis and interpretation of data. Drafting the article or revising it critically for important intellectual content. Final approval of the version to be published.

Author disclosures Authors have no conflict of interest.

Funding statement This research did not receive any specific grant from funding agencies in the public, commercial, or not-for-profit sectors.

Abbreviations: blood pressure (BP), cardiovascular (CV), chronic care model (CCM), the Finnish Quality Network (FQN), The National Institute for Health and Welfare (THL), systolic blood pressure (sBP), type 2 diabetes mellitus (T2D) 
Abstract

Aims

To investigate whether the use of a personalized care plan is associated with clinical outcomes of type 2 diabetes (T2D) treatment in real-world.

Methods

Quality of treatment was assessed using data from a yearly sample of patients with T2D visiting primary care health centres in 2012-2016. Patients were divided into three groups: 1) patient has a copy of their personalized care plan, 2) care plan exists in the patient record only or 3) patient has no care plan. Data on smoking, laboratory tests, systolic blood pressure (sBP) and statin use were collected. We compared the outcomes between the three groups in terms of proportions of patients achieving the clinical targets recommended by international guidelines.

Results

Evaluable data were available for 10,403 patients. Of these, 1,711 (16\%) had a copy of their personalized care plan, and 3,623 (35\%) had no care plan. Those who had a copy of their care plan were significantly more likely than those without to achieve the sBP target (odds ratio [OR] 1.39, 95\% confidence interval [CI] 1.29-1.51, p <0.001, adjusted for age and gender) and the low-density lipoprotein (LDL) target (OR 1.46, 95\% CI 1.34-1.58, p <0.001), and to use statins (OR 1.70, 95\% CI 1.57-1.85, p <0.001).

\section{Conclusions}

Patients who had a copy of their care plan had a better control of sBP, LDL, and used statins more likely than patients without a care plan.

\section{Introduction}

Type 2 diabetes mellitus (T2D) is a substantial public health issue and presents a large economic burden in most countries worldwide. It has been estimated that $12 \%$ of global health expenditure is spent on the treatment of diabetes and its complications [1]. Smoking, increased glycosylated haemoglobin (A1C), elevated low-density lipoprotein cholesterol (LDL) and high blood pressure (BP) are cardiovascular (CV) risk factors for micro- and macrovascular complications [2, 3]. To avoid complications, the following targets are recommended in the treatment of patients with T2D: non-smoking, A1C <7\% (53 mmol/mol), LDL $<2.5$ $\mathrm{mmol} / \mathrm{l}$, and systolic blood pressure $(\mathrm{sBP})<140 \mathrm{mmHg}[4,5]$. Studies show that all these targets are achieved in only $0.2-9.0 \%$ of patients [6, 7]. 
Alongside their medical treatment, patients with T2D should be encouraged to take responsibility for their own lifestyle changes and follow-up. A personalized care plan is a patient-centric document that requires motivational discussion between the patient and the health care professionals and includes personalized target setting and an action plan for treatment [8]. Such an approach has been shown to be associated with better self-management behaviour [9, 10], favourable A1C level [11], and BP control [12] in patients with T2D. A personalized care plan can provide a practical tool to enable shared decision making and patientcentric target setting in clinical practice. However, the implementation of a personalized care plan can be hampered by a lack of the required resources, knowledge and skills. Furthermore, health care professionals may also be reluctant to draw up a personalized care plan if they do not believe that such an approach to treatment is supported by evidence in care results [13].

Our study was designed to investigate the association between the use of a personalized care plan and clinical CV outcomes in patients with T2D in Finland. Our hypothesis was that T2D patients with a personalized care plan are more likely to reach their treatment targets, use statins more frequently and have a lower CV risk than those without such a plan. In this paper we refer to "A personalized care plan", when the patient had a copy of their care plan and to "A Care plan" when the plan was on record but not shared with the patient.

\section{Methods}

Study Population and Data Sources

This study followed a real-life cross-sectional protocol. The Finnish Quality Network (FQN) was implemented to assess the quality of primary healthcare in Finland. As part of this initiative, the quality of treatment in a yearly 2-week sample of consecutive patients with T2D (age range 15-80 years) visiting physicians (mainly general practitioners) and nurses in communal health centres in September during the years 2012-2016, was measured. Altogether 54 health centres have participated in these measurements, most centres only once, some of them every year. The number of patients in each yearly sample varied from 1853 to 3455 . The number of participating health centres varied from 18 to 41 per year. The data were usually collected manually and entered into a database by physicians and nurses, although in some cases, the data were automatically added to the FQN database by the decision support system [14]. For example, in 2016 five health centres used the decision support system.

The data included age, gender and biochemical measures (A1C, LDL, high-density lipoprotein (HDL), and total cholesterol levels) from the patient records. Patients were asked about their statin use, family history of CV disease and smoking status. Both daily and occasional smokers were considered smokers in this study. 
FQN's preferred source of sBP data is the patient's own home measurement log, wherein the mean of the four most recent double measurements is recorded. In the absence of such a log, data from the patient's official record could be used, or if none of this information was available, the average of a double measurement performed during a nurse or physician visit was used. In the present analyses, the formula developed by Niiranen et al [15] was used to normalize data from measurements performed by patients with those performed by health care professionals. This formula allows equivalent $\mathrm{CV}$ risks to be estimated from home and office BP measurements.

T2D patients were categorized in the analyses into three groups based on the status of their T2D care plan: 1 ) patient has a copy of the personalized care plan, 2) patient's care plan is only in the patient record or 3) patient has no care plan. The indicators for successful treatment were as follows: non-smoking, A1C $<7 \%$ (53 mmol/mol), LDL $<2.5 \mathrm{mmol} / \mathrm{l}, \mathrm{sBP}<133 \mathrm{mmHg}$ at home (corresponding to $140 \mathrm{mmHg}$ at the office [15]). Statin use (yes/no) was reported by the health care professional based on information from the patient and their health record. We used the FINRISK formula [16] to assess patients' overall risk for CV disease to compare the groups. The FINRISK formula an individual's percentage of an acute myocardial infraction and stroke within the subsequent 10 years.

The National Institute for Health and Welfare (THL) has designed a health and care plan form for national use in Finland [17]. It is a structured document, which includes the topic, name and ID of the patient, date the care plan has been written, names of health care professionals responsible for treatment and following subtopics: 1) the need for treatment (described by a patient), 2) targets for treatment (which have been established by the patient and health care professional together), 3) action plan, and 4) follow-up plan. An example of the personalized care plan is provided in Figure 1. It is recommended that a care plan is drawn up when the patient has at least one chronic condition. In Finland, the care plan is mainly drawn up in the primary health care setting by physicians and/or nurses. It is recommended that the patient has input into the care plan and receives a copy. Both physicians and nurses use data from care plans in the treatment of their patients with chronic conditions. In our study, the patient was considered to have a personalized care plan, if a physician or nurse observed that the plan was recorded in the patient record, and having a copy of it, if the patient reported having one when asked or if the existence of a patient copy of the care plan was confirmed in the patient record. The study protocol did not control that the care plan fulfilled the formal structure of the THL designed care plan or the number of the care plans by each health centre. In the present study, each health centre contributed records from both patients who had a copy of their care plan, and those whose plan existed only in their records. The proportion of the patients with T2D who had a care plan varied from 9 to $96 \%$ in participating health centres. 


\section{Statistical Methods}

A logistic regression analysis was performed to examine possible associations between the existence of a care plan and the chosen quality indicators. Both crude and adjusted (for age and gender) results for reaching the treatment targets were reported as odds ratios (ORs) with 95\% confidence intervals (CIs). ANOVA was used to determine differences between the three groups in comprehensive CV risk (FINRISK) standardized by age in both genders, and to calculate statistical significance of the differences. For a reference population we used the data gathered by the FQN for patients with T2D in the years 2009 - 2013. To determine which specific groups differed from each other, a post hoc test (Tukey's HSD test) was used. All analyses were carried out using IBM SPSS Statistics 20 . A p-value $<0.05$ was considered statistically significant.

\section{Ethics}

The data were collected anonymously for the improvement of the quality of care. This procedure was approved for scientific purposes by the District Ethics Committee of the University Hospital of Turku, Finland.

\section{Results}

Evaluable data were available for 10,403 patients with T2D, $48 \%$ were women, $15 \%$ were smokers, and $50 \%$ were in the age group of 66 to 80 years. The characteristics of the study population are presented in Table 1 .

Significantly greater proportions of patients with a care plan achieved the LDL and sBP treatment targets compared with the group with no personalized care plan (Table 2). The use of statin medication was more frequent in the groups with a care plan. These differences were more pronounced in the group of patients who had a copy of their personalized care plan. No significant association was found between having a personalized care plan and smoking. Patients with a personalized care plan were significantly less likely to reach the A1C target (Table 2).

The combined ten-year CV risk for acute coronary syndrome and ischemic stroke was significantly lower in males who had a copy of the personalized care plan than in the group without a personalized care plan. A care plan only in the patient record (no copy) was associated with non-significant reduction in CV risk in males. Parallel, but non-significant results, were observed among female subjects. (Table 3). 


\section{Discussion}

\section{Principal finding}

We observed that patients with T2D who had a care plan were more likely than those without such a plan to use statins and to achieve the intended target levels of LDL and sBP. The association was even stronger when a patient had a copy of their personalized care plan.

\section{Strengths and limitations}

One important strength of the present study is the large sample of primary care patients with T2D. Primary care patients rarely have only one disease to be treated - they most commonly have several concurrent medical conditions [18], and various social and economic problems [19]. Therefore, this study extends our knowledge of the benefits in an unselected population of patients with T2D of a patient-centric approach, including goal setting and a written care plan. A further strength is that our research was conducted among patients attending many health centres all over Finland, thereby representing a substantial part of the population. Thus, our methodology was not linked with any particular localized system intended to produce health care services, or any specific study protocol, and therefore we gathered results that can be generalised broadly among primary care patients with T2D in primary care.

There are some limitations in our study that need to be considered. The measures were recorded manually by health care professionals in most centres, and so misprints and selection errors may have occurred. If so, however, these errors would have affected all study group similarly. Earlier validation studies by the FQN have shown a high correlation between data collected from the patient records and data collected during the quality measurements [20]. Another limitation is that most BP values were from self-measurements. The measurement situation was uncontrolled and measurement methods can have varied between patients and health centres. On the other hand, the use of self-measurements can be considered a strength as home measured BP is known to be prognostically superior to office-measured BP [21]. Self-measurement is also a method favoured in guidelines to evaluate BP levels [22, 23].

\section{Presence of personalized care plans and associations with clinical outcomes}

In our study, only $16 \%$ of patients had received a copy of a personalized care plan from their health care professionals. Moreover, 35\% of patients did not have a care plan in their patient record. We do not know of a previous study that evaluated the prevalence of personalized care plans among patients with T2D in 
primary health care settings. Our findings suggest that writing a personalized care plan is not yet widely used in Finland.

Our study indicates that patients with a personalized care plan are more likely to meet their sBP target. This finding aligns with that of a previous study, which found that hypertension control in patients with T2D was improved with the implementation of a care programme in which both clinician and patient were involved in setting blood pressure goals and a treatment plan [12]. Also, a 2-year-follow-up study showed a positive association between the presence of a written nursing care plan and improved diastolic BP in patients with T2D [24].

In the present study, patients with a personalized care plan in the patient record or a copy of their personalized care plan were more likely than those without to use statins and reach the LDL target. Previous studies have found poor overall adherence to statin therapy in primary care patients, with non-adherence rates of $37-51 \%[25,26]$. It remains unclear whether care planning and target setting in T2D treatment influences medication adherence. Our real-world study found that having a care plan increased the likelihood of reaching the LDL target. This mirrors the findings of one previous study, which reported an improvement in LDL when using a patient-centric approach, such as behaviour support intervention, and personalized care planning [27]. However, several other studies found no such association [24, 28-31]. These differences may be due to variation in the ways the studies were carried out.

There are conflicting reports of the influence of patient-centric care and care planning on glycemic control. Goal setting improved A1C in some but not all studies reviewed in an article by Miller et al [32]. Further, in a 2-year follow-up study, while a written nursing care plan did not improve A1C in all patients with T2D, it was associated with a greater proportion of patients staying under the target level of $<7 \%(53 \mathrm{mmol} / \mathrm{mol})$ in the subgroup of patients with poor baseline glycemic control [24]. In the present study, having a personalized care plan was not associated with the likelihood of reaching the target A1C level. This finding is in line with a previous study, which also found that patients with a care plan had higher A1C levels than those without [33]. Those authors hypothesized a role of body mass index as as an explanation for their finding; those with a care plan and higher $\mathrm{A} 1 \mathrm{C}$ also tended to have higher body mass index values. We believe that the negative association between the presence of a personalized care plan and A1C in our study may have other potential explanations. Physicians and nurses may utilize the A1C but not LDL or sBP as a core indicator of the need for diabetes care. Therefore, the caregivers may not perceive a need for a care plan in a patient whose A1C is on-target, despite of high LDL or sBP. Additionally, our earlier findings showed that glucose is better treated among T2D patients compared to BP and LDL [34]. 
In our study, having a personalized care plan was not significantly associated with non-smoking. This may be because short interventions, which have been shown to be effective in smoking cessation [35, 36], are relatively common in clinical practice. Therefore, personalized care plan for T2D treatment does not provide any additional benefit for smoking cessation. Additionally, smoking cessation may be a more complex process in patient's life than the treatment of hypercholesterolemia and BP.

In the present study, the total CV risk was significantly lower in males with T2D, who had a copy of the personalized care plan than those without. This significant result was not observed among females, although there was a trend towards a smaller risk in the personalized care plan group. We are not aware of any previous study that evaluated the association between care plan and total CV risk in patients with T2D. Given that the combined control of T2D patients' CV risk factors is known to be rarely reached [6, 7], our finding that males who have a personalized care plan also have a lower CV risk is of importance, particularly given the higher overall CV risk seen in male patients [37]. The difference in results between genders may be because patient-centric discussion in consultations with female patients, even in the absence of a jointly written care plan.

\section{Clinical implications and possible mechanisms}

The goal of personalized care planning is to improve the treatment of patients with long-term chronic conditions. We believe that drawing up a care plan with the patient helps health care professionals to pay attention to patient-centred working method, shared decision making, and personalized targets with action plans. To the best of our knowledge, no previous study has evaluated the association between having a personalized care plan and different clinical treatment outcomes in a large, unselected sample of patients with T2D. Our research covering a large study population and several study years furthers the understanding of the importance of a personalized care plan in real-life. We believe that our promising results could encourage to the care plan utilization in the treatment of patients with T2D also in other western countries.

\section{Conclusions}

In conclusion, the present study shows that a personalized care plan is a promising tool to improve CV risk factors and clinical outcomes of patients with T2D in the real world. This positive finding highlights a need for controlled trials to confirm the result. It is also important to know which social and age groups benefit most from care planning and which kind of health care model is able to produce the most advantageous care plans. 


\section{Acknowledgements}

We thank Anna But from Conmedic for her great contribution in planning the statistical analyses.

\section{References}

[1] Guariguata L, Whiting D, Weil C, Unwin N. The International Diabetes Federation diabetes atlas methodology for estimating global and national prevalence of diabetes in adults. Diabetes Research and Clinical Practice 2011;94:322-32.

[2] Tesfaye S, Chaturvedi N, Eaton SE, Ward JD, Manes C, Ionescu-Tirgoviste C, et al. Vascular risk factors and diabetic neuropathy. N Engl J Med 2005;352:341-50.

[3] Stamler J, Vaccaro O, Neaton JD, Wentworth D. Diabetes, other risk factors, and 12-yr cardiovascular mortality for men screened in the Multiple Risk Factor Intervention Trial. Diabetes Care 1993;16:434-44.

[4] Perk J, De Backer G, Gohlke H, Graham I, Reiner Z, Verschuren WM et al. European Guidelines on Cardiovascular Disease Prevention in Clinical Practice (version 2012). The Fifth Joint Task Force of the European Society of Cardiology and other societies on cardiovascular disease prevention in clinical practice (constituted by representatives of nine societies and by invited experts). G Ital Cardiol (Rome) 2013;14:32892.

[5] American Diabetes Association. Standards of medical care in diabetes--2013. Diabetes Care 2013;36 Suppl 1:11.

[6] Camara S, Bouenizabila E, Hermans MP, Ahn SA, Rousseau MF. Novel determinants preventing achievement of major cardiovascular targets in type 2 diabetes. Diabetes Metab Syndr 2014;8:145-51.

[7] Rapoport M, Harel N, Shasha Y, Barkan R, Kitaee E, Buchs A et al. Achievement of partial combined control of major diabetes targets in primary care correlates with development of chronic complications in T2DM patients--A real life data. Prim Care Diabetes 2015;9:412-7. 
[8] Lorig K. Action planning: a call to action. J Am Board Fam Med 2006;19:324-5.

[9] Schillinger D, Handley M, Wang F, Hammer H. Effects of self-management support on structure, process, and outcomes among vulnerable patients with diabetes: a three-arm practical clinical trial. Diabetes Care 2009;32:559-66.

[10] Handley M, MacGregor K, Schillinger D, Sharifi C, Wong S, Bodenheimer T. Using action plans to help primary care patients adopt healthy behaviors: a descriptive study. J Am Board Fam Med 2006;19:22431.

[11] Naik AD, Palmer N, Petersen NJ, Street RL,Jr, Rao R, Suarez-Almazor M, et al. Comparative effectiveness of goal setting in diabetes mellitus group clinics: randomized clinical trial. Arch Intern Med 2011;171:453-9.

[12] Naik AD, Kallen MA, Walder A, Street RL,Jr. Improving hypertension control in diabetes mellitus: the effects of collaborative and proactive health communication. Circulation 2008;117:1361-8.

[13] Blakeman T, Macdonald W, Bower P, Gately C, Chew-Graham C. A qualitative study of GPs' attitudes to self-management of chronic disease. Br J Gen Pract 2006;56:407-14.

[14] Komulainen J, Kunnamo I. Kliinisen päätöksenteon tuki. Duodecim; lääketieteellinen aikakauskirja 2006;122:1129.

[15] Niiranen TJ, Jula AM, Kantola IM, Reunanen A. Comparison of agreement between clinic and homemeasured blood pressure in the Finnish population: the Finn-HOME Study. J Hypertens 2006;24:1549-55.

[16] Vartiainen E, Laatikainen T, Salomaa V, Jousilahti P, Peltonen M, Puska P. SLL: Sydäninfarkti- ja aivohalvausriskin arviointi FINRISKI-tutkimuksessa. Suomen Lääkärilehti 2011:4507-11.

[17] Komulainen J, Vuokko R, Mäkelä M. Rakenteinen terveys- ja hoitosuunnitelma [Structured health and care plan]. National Institute for Health and Welfare 2011:29.

[18] Ornstein SM, Nietert PJ, Jenkins RG, Litvin CB. The prevalence of chronic diseases and multimorbidity in primary care practice: a PPRNet report. J Am Board Fam Med 2013;26:518-24.

[19] Violan C, Foguet-Boreu Q, Flores-Mateo G, Salisbury C, Blom J, Freitag M, et al. Prevalence, determinants and patterns of multimorbidity in primary care: a systematic review of observational studies. PLoS One 2014;9:e102149. 
[20] Winell K, Soveri P, Heikkinen K, Paajanen M, Satuli-Autere S, Suominen L, et al. Systemaattisella laatutyöllä parannetaan valtimotautien ehkäisyä (Systematic quality improvement prevents vascular diseases). Suomen Lääkärilehti 2011;66:1835-9.

[21] Niiranen TJ, Hanninen MR, Johansson J, Reunanen A, Jula AM. Home-measured blood pressure is a stronger predictor of cardiovascular risk than office blood pressure: the Finn-Home study. Hypertension 2010;55:1346-51.

[22] Parati G, Stergiou GS, Asmar R, Bilo G, de Leeuw P, Imai Y, et al. European Society of Hypertension guidelines for blood pressure monitoring at home: a summary report of the Second International Consensus Conference on Home Blood Pressure Monitoring. J Hypertens 2008;26:1505-26.

[23] Pickering TG, Miller NH, Ogedegbe G, Krakoff LR, Artinian NT, Goff D, American Heart Association, American Society of Hypertension, Preventive Cardiovascular Nurses Association. Call to action on use and reimbursement for home blood pressure monitoring: a joint scientific statement from the American Heart Association, American Society of Hypertension, and Preventive Cardiovascular Nurses Association. J Cardiovasc Nurs 2008;23:299-323.

[24] Cardenas-Valladolid J, Salinero-Fort MA, Gomez-Campelo P, de Burgos-Lunar C, Abanades-Herranz JC, Arnal-Selfa R, et al. Effectiveness of standardized Nursing Care Plans in health outcomes in patients with type 2 Diabetes Mellitus: a two-year prospective follow-up study. PLoS One 2012;7:e43870.

[25] Bermingham M, Hayden J, Dawkins I, Miwa S, Gibson D, McDonald K, et al. Prospective analysis of LDL-C goal achievement and self-reported medication adherence among statin users in primary care. Clin Ther 2011;33:1180-9.

[26] Natarajan N, Putnam RW, Yip AM, Frail D. Family practice patients' adherence to statin medications. Can Fam Physician 2007;53:2144-5.

[27] Katon WJ, Lin EH, Von Korff M, Ciechanowski P, Ludman EJ, Young B, et al. Collaborative care for patients with depression and chronic illnesses. N Engl J Med 2010;363:2611-20.

[28] Thom DH, Ghorob A, Hessler D, De Vore D, Chen E, Bodenheimer TA. Impact of peer health coaching on glycemic control in low-income patients with diabetes: a randomized controlled trial. Ann Fam Med 2013;11:137-44.

[29] Frosch DL, Uy V, Ochoa S, Mangione CM. Evaluation of a behavior support intervention for patients with poorly controlled diabetes. Arch Intern Med 2011;171:2011-7. 
[30] Glasgow RE, Nutting PA, King DK, Nelson CC, Cutter G, Gaglio B, Rahm AK, Whitesides H. Randomized effectiveness trial of a computer-assisted intervention to improve diabetes care. Diabetes Care 2005;28:33-9.

[31] Hiss RG, Armbruster BA, Gillard ML, McClure LA. Nurse care manager collaboration with community-based physicians providing diabetes care: a randomized controlled trial. Diabetes Educ 2007;33:493-502.

[32] Miller CK, Bauman J. Goal setting: an integral component of effective diabetes care. Curr Diab Rep 2014;14:x.

[33] Umeh K. Personal care plans and glycaemic control: the role of body mass index and physical activity. Br J Nurs 2017;26:543-51.

[34] Varilo S, Santaholma J, Soveri P, Winell K. Does continuous quality development bring better results? Comparison of the results between the old and the new centres in the care of the persons with type 2 diabetes 2006.

[35] Rice VH, Hartmann-Boyce J, Stead LF. Nursing interventions for smoking cessation. Cochrane Database Syst Rev 2013;(8):CD001188. doi:CD001 188.

[36] Stead LF, Bergson G, Lancaster T. Physician advice for smoking cessation. Cochrane Database Syst Rev 2008;(2):CD000165. doi:CD000165.

[37] Hyvarinen M, Qiao Q, Tuomilehto J, Soderberg S, Eliasson M, Stehouwer CD. The difference between acute coronary heart disease and ischaemic stroke risk with regard to gender and age in Finnish and Swedish populations. Int J Stroke 2010;5:152-6. 


\begin{tabular}{lcccc} 
& Total $(\mathrm{n} \%)$ & No care plan $(\mathrm{n})$ & $\begin{array}{c}\text { A personalized care } \\
\text { plan }(\mathrm{n})\end{array}$ & $\begin{array}{c}\text { A copy of the } \\
\text { personalized care } \\
\text { plan }(\mathrm{n})\end{array}$ \\
\hline Male & $5,388(52 \%)$ & 1,851 & 2,643 & 894 \\
Female & $5,015(48 \%)$ & 1,772 & 2,426 & 817 \\
Age group (years) & & & & \\
\hline$<51$ & $1,203(12 \%)$ & 408 & 565 & 230 \\
$51-65$ & $3,972(38 \%)$ & 1,350 & 1,910 & 712 \\
$66-80$ & $5,228(50 \%)$ & 1,865 & 2,594 & 769 \\
\hline All $(\mathrm{n} \%)$ & $10,403(100 \%)$ & $3,623(35 \%)$ & $5,069(49 \%)$ & $1,711(16 \%)$ \\
\hline
\end{tabular}

Table 1. Basic characteristics of the study population. 


Crude OR $\quad 95 \% \mathrm{Cl} \quad$ P-value $\quad \begin{gathered}\text { Adjusted* } \\ \text { OR }\end{gathered} \quad 95 \% \mathrm{Cl} \quad$ P-value

HbA1c
$<7 \%$
$(53 \mathrm{mmol} / \mathrm{mol})$

\begin{tabular}{lcccccc} 
No plan & reference & \multicolumn{5}{c}{ reference } \\
No copy & 0.89 & $(0.82-0.97)$ & 0.006 & 0.89 & $(0.82-0.97)$ & 0.008 \\
Copy & 0.86 & $(0.77-0.96)$ & 0.008 & 0.87 & $(0.78-0.97)$ & 0.017
\end{tabular}

Table 2. The association between $\mathrm{HbA}_{1 \mathrm{c}}$, LDL, use of statin, sBP and smoking and the three groups of type 2 diabetic patients with no personalized care plan (no plan), a personalized care plan in patient record (no copy) and a copy of the personalized care plan (copy). 
LDL

$<2.5 \mathrm{mmol} / \mathrm{l}$

\begin{tabular}{lcccccr} 
No plan & reference & \multicolumn{5}{c}{ reference } \\
No copy & 1.28 & $(1.21-1.35)$ & $<0.001$ & 1.26 & $(1.19-1.33)$ & $<0.001$ \\
Copy & 1.47 & $(1.36-1.60)$ & $<0.001$ & 1.46 & $(1.34-1.58)$ & $<0.001$
\end{tabular}

Use of statin

\begin{tabular}{lcccccr} 
No plan & reference & \multicolumn{5}{c}{ reference } \\
No copy & 1.38 & $(1.31-1.45)$ & $<0.001$ & 1.35 & $(1.28-1.42)$ & $<0.001$ \\
Copy & 1.72 & $(1.59-1.86)$ & $<0.001$ & 1.70 & $(1.57-1.85)$ & $<0.001$
\end{tabular}

SBP

$<133 \mathrm{mmHg}$

\begin{tabular}{lcccccr} 
No plan & reference & \multicolumn{5}{c}{ reference } \\
No copy & 1.22 & $(1.16-1.28)$ & $<0.001$ & 1.23 & $(1.17-1.3)$ & $<0.001$ \\
Copy & 1.38 & $(1.28-1.50)$ & $<0.001$ & 1.39 & $(1.29-1.51)$ & $<0.001$
\end{tabular}

Smoking

\begin{tabular}{lcccccc} 
No plan & reference & \multicolumn{5}{c}{ reference } \\
No copy & 0.89 & $(0.83-0.97)$ & 0.005 & 0.92 & $(0.85-1.00)$ & 0.048 \\
Copy & 0.97 & $(0.87-1.09)$ & 0.599 & 0.96 & $(0.85-1.08)$ & 0.496
\end{tabular}

* adjusted for age and gender

Table 3. The total cardiovascular risk according to FINRISK (\%) in the three patient groups: patients with no personalized care plan (no plan), patients having a personalized care plan only in the health care record (no copy), and patients having a copy of the personalized care plan (copy), means, standardized for age with $95 \%$ confidence intervals (CIs) and Tukey's results presented.

\begin{tabular}{|c|c|c|c|c|c|c|c|}
\hline $\begin{array}{l}\text { Total } \\
\text { risk }\end{array}$ & & $\begin{array}{c}\text { Male } \\
\text { Standardized } \\
\text { mean }\end{array}$ & $95 \% \mathrm{Cl}$ & P-value & $\begin{array}{c}\text { Female } \\
\text { Standardized } \\
\text { mean }\end{array}$ & $95 \% \mathrm{Cl}$ & P-value \\
\hline & No plan & 13.04 & $(12.48-13.6)$ & reference & 8.08 & $\begin{array}{c}(7.69- \\
8.46)\end{array}$ & reference \\
\hline & No & 12.98 & (12.54- & 0.984 & 7.78 & (7.47- & 0.440 \\
\hline
\end{tabular}


copy

Copy

\section{${ }^{* *}$ standardized for age}




\section{Figure 1. Example of a personalized care plan for a patient with type 2 diabetes}

\section{Personal data of the patient}

\section{The compiler of the care plan}

Date of documentation

\section{Diagnosis}

All concurrent diagnoses in patient's language (in brackets with international classification of disease (ICD10) codes)

\section{Need for treatment}

Patient describes

\section{Targets of treatment}

Concrete and realistic targets discussed and agreed upon by the patient and the physician and/or nurse.

Takes into account local processes and international guidelines.

For example:

Maintenance of BP: under 135/75 mmHg in home measurements (now 143/82 mmHg). Blood pressure will be calculated four times per year over four-day periods of double measurements.

Maintenance of LDL: under $2.5 \mathrm{mmol} / \mathrm{L}$ (now $3.2 \mathrm{mmol} / \mathrm{L}$ )

Smoking: Answer the motivational questions once a month until next visit

Maintenance of long-term blood sugar (A1C): under $53 \mathrm{mmol} / \mathrm{mol}$ (now $60 \mathrm{mmol} / \mathrm{mol}$ )

Maintenance of fasting glucose in home measurements: average under $7 \mathrm{mmol} / \mathrm{L}$ (now $7.6 \mathrm{mmol} / \mathrm{L}$ )

Maintenance of postprandial glucose values: none above $10 \mathrm{mmol} / \mathrm{L}$ (now twice a week)

\section{Support, action, follow-up and evaluation:}

\section{For example}

Additional instructions for home monitoring

Changes in medication

Self-management actions discussed during consultation visit

Positive feedback to the patient on achievement of goals

Contact details

The date of the next control visit and previous laboratory test

\section{Medication}

List of the names and doses of the patient's medication. 